\title{
Effects of long-term treatment with estrogen and medroxyprogesterone acetate on synapse number in the medial prefrontal cortex of aged female rats
}

\author{
Nioka C. Chisholm, MA ${ }^{a, 2}$ and Janice M. Juraska, PhD ${ }^{a, b, 1}$ \\ aDepartment of Psychology, University of Illinois at Urbana - Champaign, Champaign, Illinois \\ 61820 \\ ${ }^{b}$ Neuroscience Program, University of Illinois at Urbana - Champaign, Champaign, Illinois 61820
}

\section{Abstract}

Objective-The present study investigated the effects of long-term hormone treatment, including the most commonly prescribed progestin, medroxyprogesterone acetate, during aging on synaptophysin labeled boutons, a marker of synapses, in the medial prefrontal cortex (mPFC) of rats.

Methods-Female Long Evans hooded rats were ovariectomized at middle age (12-13 months) and were placed in one of 4 groups: no replacement $(n=5), 17 \beta$-estradiol alone $(n=6)$, estradiol and progesterone $(n=7)$ or estradioland medroxyprogesteroneacetate $(n=4)$. Estradiol was administered in the drinking water and progestagens were administered via subcutaneous pellets that were replaced every 90 days. Following seven months of hormone replacement, animals were sacrificed and brains were stained for synaptophysin, a membrane component of synaptic vesicles. The density of synaptophysin labeled boutons was quantified in the mPFC using unbiased stereology and multiplied by the volume of the MPFC to obtain total number.

Results-Animals receiving estradiol and medroxyprogesterone acetate had significantly more synaptophysin labeled boutons in the medial prefrontal cortex than animals not receiving replacement $(\mathrm{p}<.03)$ and those receiving estradiol and progesterone ( $\mathrm{p}<.02)$. In addition, there was a non significant trend for animals receiving estradiol alone to have more synapses than those receiving estradiol and progesterone.

Conclusions-This study is the first to examine the effects of estradiol and medroxyprogesterone acetate during rat aging on cortical synaptic number. Estradiol with medroxyprogesterone acetate, but not progesterone, resulted in a greater number of synapses in the mPFC during aging than no replacement.

\section{Keywords}

estrogen; MPA; synaptophysin; hormone therapy; progesterone

\footnotetext{
${ }^{1}$ To whom correspondence should be addressed: Department of Psychology, University of Illinois, 603 E. Daniel Street, Champaign, IL 61820. Fax: (217) 244-5876. jjuraska@illinois.edu.

${ }^{2}$ Author previously published as Nioka C. Lowry

There is no conflict of interest for either author.
} 


\section{Introduction}

Menopause in humans is associated with a loss of ovarian hormones and this decline in estrogen and progesterone has been linked to several of the symptoms related to menopause. Hormone therapies including Premarin (conjugated equine estrogens; CEE) and Prempro (CEE in combination with medroxyprogesterone acetate; MPA), have been approved to alleviate these symptoms. In women with a uterus, MPA, a synthetic analogue of progesterone, is administered in combination with estrogen therapy to prevent endometrial hyperplasia ${ }^{1}$. Along with alleviating some of the symptoms of menopause, hormone treatment has beneficial effects on cognition ${ }^{2-4}$. However, results from the Women's Health Initiative indicated that CEE alone or CEE administered with MPA results in an increased risk of stroke and dementia ${ }^{5-7}$. There is evidence that the timing of hormone replacement onset is an important factor and may explain the negative findings of the Women's Health Initiative studies ${ }^{8-10}$.

Although data on the cognitive effects of hormone treatment in post-menopausal women seem inconsistent, several neurobiological studies have found that ovarian hormones increase synapses in the hippocampus of both young adult rats and non human primates. Ovariectomy decreased synapses in the CA1 region of the hippocampus ${ }^{11}$ and estradiol administration increased the density of spines and synapses in the CA1 of young rats and non human primates ${ }^{12-15}$. Chronic treatment with CEE increased synaptic density in the CA1 of young adult rats ${ }^{16,17}$. The synaptic response to estrogen is thought to involve estrogen receptor (ER) $a$ and ER $\beta$, but the percentage of ERa labeled synapses ${ }^{18}$ and the amount of ER $\beta^{19}$ decreases in the hippocampus during aging indicating that the aged brain might respond differently to estradiol. Indeed, estradiol increased synaptophysin, a membrane component of synaptic vesicles, in the CA1 of young animals but not in middleaged rats ${ }^{20}$. Although estradiol increased NR1, a subunit of the NMDA receptor, in the hippocampus of aged animals, there was no increase in synapse number ${ }^{13}$.

Fewer studies have looked at the effects of hormone treatment on the prefrontal cortex (PFC), which exhibits greater neuroanatomical loss in both humans and other animals during aging than the hippocampus ${ }^{21}$. Several studies have identified the human PFC as a region that has greater decline in gray matter volume during aging than other brain areas 22,23 . This change in volume is accompanied by age-related losses of dendrites and spines ${ }^{24,25}$. There are also age-related losses of dendrites and spines in the PFC of non-human primates ${ }^{26,27}$ and rats ${ }^{28-30}$. Similar to the hippocampus, estrogen can alter the structure of the PFC. Ovariectomy decreased spine density in the young adult rat $\mathrm{PFC}^{31}$ and estradiol benzoate increased spine synapse density in the PFC of young non-human primates ${ }^{32}$. Furthermore, long-term cyclic estradiol treatment increased dendritic spine density in the PFC of both young and aged rhesus monkeys ${ }^{33,34}$, indicating that estradiol may affect the number of synapses in the aged PFC. In addition, intact females lose fewer spines during aging in the mPFC than males which may be due to the continued secretion of estrogen and progesterone during estropause in rats ${ }^{29}$. To our knowledge, no study has examined the effects of progestogens on the PFC.

Progestogens can alter the effects of estrogen on behavior in aging females ${ }^{35,36}$ and may also change the effect of estrogen on synaptic numbers. The few studies that have investigated the effects of progestogens on synapse number have examined the hippocampus. Although progesterone administered alone increased the density of synaptophysin in young adult rhesus monkeys, progesterone administered with estrogen resulted in densities similar to ovariectomized controls ${ }^{15}$. A more recent study found that estradiol in combination with progesterone increased synaptophysin in hippocampal CA1 of young rats but not middle-aged or aged animals ${ }^{20}$. MPA is the progestin most commonly 
prescribed to women and very little is known about the neural effects of long-term use. Both MPA and progesterone bind with high affinity to the progesterone receptor as well to the androgen and glucocorticoid receptors ${ }^{37-39}$. However, progesterone is readily metabolized to allopregnanolone ${ }^{40}$ whereas MPA inhibits the enzymes needed for this conversion ${ }^{41-43}$. Differences in mechanisms of action between these progestogens may result in divergent neural responses. Surprisingly only one study has evaluated the effects of MPA on synapse number. Chronic treatment with MPA alone or in combination with CEE resulted in an increase in the number of synapses in the hippocampus of young rats ${ }^{17}$. It is currently unknown if long-term treatment with MPA alters synapse number in the aged brain.

The potential effects of estrogen and the addition of progestogens on the number of synapses in the PFC are especially pertinent, given the dramatic changes in the PFC during aging. Therefore, the present study examined the effects of long-term chronic hormone treatment on the number of synaptophysin labeled boutons in the mPFC of aging females.

\section{Methods}

\section{Subjects}

Subjects were 22 female Long Evans hooded rats purchased from Charles River Laboratories as retired breeders at the age of 11-12 months. Due to limited availability from the supplier, animals were run in two experimental cohorts. Animals from the same group were pair- or triple- housed, in clear Plexiglass cages in a temperature-controlled environment on a 12:12-hr light-dark cycle. Animals from these cohorts were used in two behavioral experiments prior to sacrifice ${ }^{36,44}$. Standard rodent chow (Harlan 8604 Tekland) and water were available ad libitum to all animals, except during behavioral procedures during which the animals were maintained at $85-90 \%$ of their normal body weight. All rats were handled, checked for health problems (tumors), and weighed weekly. At sacrifice, both body and uterine weight were measured. Animal care and experimental procedures were in accordance with National Institutes of Health guidelines and were approved by the Institutional Animal Care and Use Committee.

\section{Hormone Treatment}

All subjects were ovariectomized (OVX) at 12-13 months, because intact female rats continue to secrete low levels of ovarian hormones during aging $29,35,45$. Subjects were anesthetized with $4 \%$ isoflurane and ovaries were removed via bilateral incisions. Animals were administered the analgesic, carprofen $(0.05 \mathrm{mg} / \mathrm{kg}$ delivered intraperitoneally) prior to surgery and again 12 hours later, in accordance with animal care policy. Subjects were housed individually for five days following surgery to allow for recovery and then returned to pair- or triple-housed conditions. Hormone administration was initiated the day of surgery and continued until sacrifice. Animals were randomly assigned into the following four groups: no replacement $(n=5), 17 \beta$-estradiol $\left(E_{2}\right)(n=6), E_{2}$ and MPA $\left(E_{2}+\right.$ MPA $)(n=$ $4), E_{2}$ and progesterone $\left(E_{2}+P\right)(n=7)$.

$17 \boldsymbol{\beta}$-estradiol $\left(E_{2}\right)$ Administration-As in Lowry et al. ${ }^{36}$, all groups receiving estradiol were given $E_{2}$ in their drinking water. A pilot study indicated that an $E_{2}$ dose of $47 \mathrm{ug} / \mathrm{kg} / \mathrm{day}$ produced estrogen levels in the physiological range for this age group $(25-30 \mathrm{pg} / \mathrm{ml})^{29,35}$. $\mathrm{E}_{2}$ was first dissolved in $95 \%$ ethanol $(2 \mathrm{mg} / \mathrm{ml})$ and then dissolved in water as described in Gordon et al. ${ }^{46}$. Water bottles were filled with new estrogen water every third day and stock estrogen water was stored in a dark refrigerator. Water consumption was measured for each cage and remained between $60-80 \mathrm{ml} / \mathrm{kg} / \mathrm{day}$ throughout the experiment for all groups. This range in water consumption resulted in $E_{2}$ doses between $40-55 \mathrm{ug} / \mathrm{kg} / \mathrm{day}$. The dose of $E_{2}$ was calculated by taking the amount of water consumed by a cage and dividing by the sum 
of the weights in that cage. This value was then multiplied by the $\mathrm{E}_{2}$ concentration in the water.

Progestogen Treatment-On the day of OVX, one hormone pellet of either progesterone or MPA was inserted through a small incision in the nape of the neck in the appropriate groups. Progesterone pellets were made from silastic tubing (Dow Corning) packed with crystalline hormone. Studies have shown that $40 \mathrm{~mm}$ implants produce hormone levels between those found in aging female rats in persistent estrus and persistent diestrus $^{47}$. The MPA pellets $(1.5 \mathrm{mg}$ ) were purchased from Innovative Research of America. The $1.5 \mathrm{mg} 90$-day release pellets result in a dose similar to that in women taking $2.5 \mathrm{mg}$ per day when expected daily release and average body weight are factored in. Progesterone and MPA pellets were replaced every 90 days. All other groups received sham surgeries at the time of pellet replacement.

\section{Histology}

At 19-20 months, after approximately 7 months of hormone treatment, rats were deeply anesthetized with sodium pentobarbital $(2 \mathrm{mg} / \mathrm{kg}$ of a $50 \mathrm{mg} / \mathrm{ml}$ solution) and perfused intracardially with phosphate buffered saline followed with a solution of $4 \%$ paraformaldehyde, $4 \%$ sucrose and $1.4 \%$ sodium cacodylate in $\mathrm{dH}_{2} \mathrm{O}$. The brains were removed and stored in the same solution for 24 hours. Brains were then transferred to a sodium cacodylate buffer solution and shipped at room temperature to Neuroscience Associates (Knoxville, TN) for sectioning. Briefly, brains were cryoprotected in a glycerol and DMSO-based formulation prior to sectioning. Fixed brains from each cohort were embedded together in a gelatin block that was frozen-sectioned at $30 \mu \mathrm{m}$. Every tenth section was stained for synaptophysin, a membrane component of synaptic vesicles, and other sections were saved. Adjacent sections were stained with methylene blue/azure II, a cell body stain, in our laboratory for volume calculations.

\section{Volume estimation}

Using cytoarchitectonic criteria ${ }^{48,49}$ the ventral mPFC (prelimbic (PL) and infralimbic (IL)) regions were parcellated at $31.25 \times$ using a camera lucida on coded slides stained with methylene blue/azure II. The ventral mPFC was parcellated starting with the first section containing white matter continuing through the first section in which the genu of the corpus callosum appeared. This resulted in parcellation of both hemispheres in four to five sections per subject. Parcellation criteria used for the ventral mPFC have been described in Markham et al. ${ }^{50}$. For the present study, the PL and IL were not separated. The border between PL and dorsal anterior cingulated (ACd) is marked by a broadening of layer $\mathrm{V}$ and an increase in the density of layer 3 cells in the ACd as compared to the PL (Figure 1). Layers 2/3 and 5/6 were measured separately (rat mPFC lacks layer 4). Camera lucida tracings were scanned into a computer and Image $\mathrm{J}$ (version 1.44, 2010) was used to measure the area of each parcellation. The volume was then calculated by multiplying this area by the mounted tissue thickness between sections. Mounted tissue thickness was measured by determining the difference between the focal depth of the top and bottom of the tissue using the StereoInvestigator software program (MicroBrightField). Ten measurements of thickness were taken per animal. An average section thickness was calculated per animal and used in the calculations for that animal. Mounted section thickness was equivalent among all groups. Randomly, animals were selected for re-parcellation and the area of the ventral mPFC was recalculated. This was done to insure consistency in parcellation criterion. Area measurements remained within $5 \%$ between parcellation drawings for a given animal. 


\section{Synapse Number}

Synaptophysin boutons were quantified in the PL and IL of the mPFC using the StereoInvestigator software program (MicroBrightField). The optical disector was used to obtain stereologically unbiased counts of synaptophysin density in each layer of the mPFC (Figure 2). Using this program, contours were drawn of layers $2 / 3$ and layers $5 / 6$ in the ventral mPFC. Both hemispheres from two sections containing the $\mathrm{mPFC}$ were used for counts. At least 200 synaptophysin boutons were counted within each layer $(2 / 3,5 / 6)$ for each subject. The area of the counting frame used was $4 \mu \mathrm{m} \times 4 \mu \mathrm{m}$ with approximately 20 counting sites per section in both layers $2 / 3$ and layers 5/6. Section thickness was used for dissector height excluding the $.5 \mu \mathrm{m}$ guard zones. Section thickness was measured at every fifth site on counted sections. Boutons fully inside the counting frame or those that contact the 'inclusion' line without contacting the 'exclusion' line were included in counts (Figure 2). Average counts for each layer were divided by the volume of the counting frame to get the density of synaptophysin boutons. This density was then multiplied by the volume of the mPFC to obtain synapse number.

\section{Statistical Analysis}

Body weights, uterine weights, volume of the $\mathrm{mPFC}$, and the total number of synaptic boutons, as well as those in layers $2 / 3$ and in layers $5 / 6$, were each analyzed using a one-way ANOVA with cohort as a covariate. Fisher's LSD tests were used for all post hoc comparisons.

\section{Results}

\section{Body and Uterine Weights}

The ANOVA revealed a significant effect of treatment on body weight $(\mathrm{p}<.01)$. Post-hoc Fisher's LSD revealed that the no replacement group weighed significantly more than all groups that received hormone treatment $\left(\mathrm{E}_{2}: \mathrm{p}<.01 ; \mathrm{E}_{2}+\mathrm{P}: \mathrm{p}<.01 ; \mathrm{E}_{2}+\right.$ MPA: $\left.\mathrm{p}<.01\right)$. No other comparisons reached significance (Table 1.)

The ANOVA resulted in a significant effect of treatment on uterine weight $(\mathrm{p}<.02)$. Posthoc Fisher's LSD revealed that uterine weight in the no replacement group was significantly lower than all groups that received hormone treatment, indicating that hormone treatment was physiologically effective $\left(\mathrm{E}_{2}: \mathrm{p}<.01 ; \mathrm{E}_{2}+\mathrm{P}: \mathrm{p}<.01 ; \mathrm{E}_{2}+\right.$ MPA: $\left.\mathrm{p}<.01\right)$.

\section{Synapse Number}

The volume of the mPFC was not significantly different between any of the groups. There was an overall effect of hormone treatment on the total number of synaptophysin boutons in the mPFC ( $\mathrm{p}<.05)$. Post hoc tests revealed that animals receiving $\mathrm{E}_{2}+$ MPA had more synaptophysin boutons than those receiving no replacement $(\mathrm{p}<.03)$ and $\mathrm{E}_{2}+\mathrm{P}(\mathrm{p}<.02)$. There was a non significant trend for animals receiving estrogen alone to have more synaptophysin boutons than those receiving $E_{2}+P(p<.09)$ (Figure 3). For layers $2 / 3$, hormone treatment did not alter synapse number $(\mathrm{p}=.17$ ) (Figure $4 \mathrm{a})$. Analysis of layers $5 / 6$ found a significant effect of hormone treatment on the number of synaptophysin labeled boutons $(\mathrm{p}=.04)$. Post hoc tests revealed that animals receiving $\mathrm{E}_{2}+$ MPA had more synaptophysin boutons that those receiving no replacement $(\mathrm{p}<.02)$ and $\mathrm{E}_{2}+\mathrm{P}(\mathrm{p}<.02)$ (Figure 4b).

\section{Discussion}

Long-term treatment with estradiol in combination with MPA to middle aged female rats resulted in greater numbers of synapses, as indicated by synaptophysin labeled boutons, in 
the $\mathrm{mPFC}$ as compared to ovariectomized controls. This is in agreement with the only other study to evaluate the effects of MPA on synapse number which found that MPA alone or administered with CEE increased synapses in the CA1 of young adult rats ${ }^{17}$. Also, we have preliminary data showing that animals receiving estradiol in combination with MPA cyclically have greater numbers of synapses than ovariectomized controls ${ }^{21}$. Importantly, synapse number decreases during aging 51,52 and several measures related to synapse number are altered by aging in the PFC. There are age-related losses of dendrites and spines in the PFC of humans ${ }^{24,25}$, non human primates ${ }^{26,27}$, and rats ${ }^{28-30}$. These changes have been linked to age related cognitive decline. For example, during aging, non human primates experience a decrease in the density of axospinal synapses in the PFC which correlates with acquisition of a delayed non-match to sample task ${ }^{53}$. Furthermore, age related deficits on an object recognition memory task are associated with decreases in dendritic spine density in the mPFC of rats ${ }^{30}$. Because aging has been associated with a loss of synapses and this loss has been linked to cognitive deficits, the greater number of synapses in the aged PFC following long-term exposure to estradiol and MPA could result in beneficial effects on behavioral tasks mediated by the mPFC.

However, few studies have evaluated the effects of estradiol in combination with MPA on cognition. MPA administered without estradiol impaired performance on the water radial arm maze and water maze ${ }^{54,55}$. Although progesterone enhanced performance on the water maze and object recognition, MPA alone did not alter performance ${ }^{56}$. A subset of the animals in the present study was tested on the water maze, and estradiol plus MPA resulted in impaired performance as compared to other hormone treated groups ${ }^{36}$. In contrast, when many of the same subjects were tested on a delayed alternation t-maze task, treatment with estradiol in combination with MPA resulted in animals requiring fewer sessions to reach criterion ${ }^{44}$. The brain region mediating performance on a task may play an important role in determining the behavioral outcome of hormone treatment, and the studies that have found that MPA impairs cognition have used tasks that rely heavily on the hippocampus ${ }^{36,54,55}$. The present study found that estradiol plus MPA results in more synaptophysin labeled boutons as compared with ovariectomized controls in the mPFC, suggesting that this combination of hormone treatment may be beneficial on tasks that rely more heavily on the mPFC.

Unlike estradiol and MPA, estradiol plus progesterone did not affect the number of synaptophysin labeled boutons. Although MPA is a synthetic analogue of progesterone, studies have found that these two progestogens do not share identical biological properties. MPA has a higher affinity for androgen and glucocorticoid receptors than progesterone ${ }^{57}$, and progesterone is readily metabolized to allopregnanolone ${ }^{40}$ while MPA inhibits the enzymes needed for this conversion ${ }^{41-43}$. Several studies have found that these two progestogens result in differential neural outcomes. For example, MPA, but not progesterone, suppresses cytokine production after an inflammatory stimulus in vitro ${ }^{38}$. In addition, in vitro studies have found that progesterone protected against kainic acid-induced neuronal loss while MPA did not ${ }^{58}$. Progesterone alone and in combination with estrogen protected against glutamate toxicity while MPA was not protective and prevented estradiol's influence on neuroprotection ${ }^{59,60}$. Also, treatment with estradiol and progesterone but not MPA, increased proliferation of neuroprogenitor cells in culture ${ }^{61}$. Furthermore, progesterone increased levels of brain-derived neurotrophic factor while MPA decreased this measure ${ }^{62}$. Although MPA and progesterone treatments without estrogen decreased levels of glutamic acid decarboxylase in the hippocampus, this decrease was only significant in those receiving MPA ${ }^{55}$. Interestingly, most of these studies indicate a beneficial effect of progesterone on the measures evaluated, which was not found in the present study; however none of these studies examined synapse number or the consequence of neuroprotection for normal aging. The current study administered hormones for approximately seven months in 
order to evaluate the long-term effects of hormone treatment, and many of the previous studies have used acute treatments. It has been found that chronic treatment of ovarian hormones results in different outcomes than more acute treatments ${ }^{63-65}$. It is possible that long-term hormone treatment results in receptors that are less sensitive and that these two progestagens differ in this long term dynamic. Furthermore, previous studies comparing these progestogens have examined the effects on the hippocampus, and it is known that the anatomical structure of the PFC is particularly vulnerable to aging, while the hippocampus is not (reviewed in ${ }^{21}$ ). It is possible that because the hippocampus and mPFC respond differently to aging they are differentially affected by progestogens administered during this time.

Estrogen is known to alter several aspects of synaptic communication in young rats. For example, estrogen administered to ovariectomized animals, returns synaptophysin levels and spine densities in the CA1 to levels observed in intact controls ${ }^{11,20,66}$. Also, ovariectomy decreases synaptophysin levels in the inner layer of the dentate gyrus and estrogen restores this ${ }^{67}$. However, the aged hippocampus appears to be less responsive to the effects of estrogen. Estrogen treatment did not increase synapse density in the CA1 of aged animals ${ }^{13}$ and there was decreased amounts of synaptic ERa immunoreactivity in this brain region ${ }^{18}$. In addition, estradiol increased the amount of synaptophysin and opioid peptides in the CA1 and dentate gyrus of young animals, but did not alter the amount in aged animals ${ }^{20}$. The present study found that long-term estrogen marginally increased synapses in the aged $\mathrm{mPFC}$ suggesting that in contrast to the hippocampus, the mPFC may remain responsive to estrogens during aging. This is in agreement with previous studies in non human primates. Long-term cyclic treatment with estradiol increased apical and basal dendritic spine density in the PFC of aged female rhesus monkeys and reversed age-related impairments on a delayed response task mediated by the $\mathrm{PFC}^{34,68}$. It is important to note that the means in the present study were in the direction of estrogen treated animals having more synapses although it did not reach significance. Studies have found that rodent diets high in phytoestrogens result in a greater density of spines in both the hippocampus and PFC 69 . As in most of the literature, animals in the present study were maintained on a standard rodent diet and it is possible that the low levels of soy in the diet increased the number of synaptophysin boutons in our no replacement animals minimizing differences between groups $^{32}$. The differences that were found are especially notable in light of this possibility.

The effects of estrogen on synapse number have been shown to be mediated through estrogen receptors ${ }^{70,71}$. However, because the effects of estrogen alone were subtle in the current study and the addition of MPA led to significantly more synapses as compared to no replacement, it seems likely that this effect was mediated by a different mechanism.

Research suggests that synapse number is also regulated by IGF-1. IGF-1 null animals have decreased dendritic length and spines in the frontoparietal cortex ${ }^{72}$ and over expression of IGF-1increases the number of synapses in the dentate gyrus ${ }^{73}$. Importantly, IGF-1 protein levels are decreased during aging ${ }^{74}$ and modulated by steroid hormones ${ }^{75}$. Estrogen alone has been found to decrease IGF-1levels; however, estrogen administered with MPA resulted in an increase in IGF-1 in post-menopausal women ${ }^{76}$ while estradiol administered with natural progesterone does not ${ }^{77}$. Therefore, the effects of estrogen in combination with MPA on synapse number seen in the current study may be mediated in part by increasing IGF-1 levels.

Given the vulnerability of the PFC to the effects of aging, the alteration of the mPFC by hormone treatment during aging may have implications for age-related cognitive deficits. Results from the current study indicate that the aged PFC remains responsive to certain hormone treatments and thus these treatments may protect against age-related cognitive deficits. Indeed, treatment with acute estrogen alone given to postmenopausal women 
benefited tasks relying on the PFC to a greater extent than those relying on the hippocampus ${ }^{3}$. In addition, women not receiving estrogen replacement performed worse on several PFC dependant tasks than those receiving hormone treatment ${ }^{78}$. Future studies in humans should evaluate the effects of long-term hormone treatment, including the addition of a progestogen on PFC dependant tasks.

\section{Conclusions}

This study identifies the prefrontal cortex as a brain region that is altered by long-term chronic hormone treatment during aging in the rat. Specifically, treatment with estradiol and MPA resulted in more synaptophysin labeled boutons in the $\mathrm{MPFC}$ relative to females with no replacement or replacement with estradiol and progesterone. These findings provide insight into the neural effects of long-term hormone treatment.

\section{Acknowledgments}

We would like to thank Stephanie Painter and Melissa Yates for their essential help in initiating this study. Supported by NIA AG 022499

\section{References}

1. Whitehead MI, King RJ, McQueen J, Campbell S. Endometrial histology and biochemistry in climacteric women during oestrogen and oestrogen/progestogen therapy. J R Soc Med. 1979; 72(5): 322-327. [PubMed: 552525]

2. LeBlanc ES, Janowsky J, Chan BK, Nelson HD. Hormone replacement therapy and cognition: systematic review and meta-analysis. JAMA. 2001; 285(11):1489-1499. [PubMed: 11255426]

3. Krug R, Born J, Rasch B. A 3-day estrogen treatment improves prefrontal cortex-dependent cognitive function in postmenopausal women. Psychoneuroendocrinology. 2006; 31(8):965-975. [PubMed: 16831520]

4. Joffe H, Hall JE, Gruber S, et al. Estrogen therapy selectively enhances prefrontal cognitive processes: a randomized, double-blind, placebo-controlled study with functional magnetic resonance imaging in perimenopausal and recently postmenopausal women. Menopause. 2006; 13(3):411-422. [PubMed: 16735938]

5. Wassertheil-Smoller S, Hendrix SL, Limacher M, et al. Effect of estrogen plus progestin on stroke in postmenopausal women: the Women's Health Initiative: a randomized trial. JAMA. 2003; 289(20):2673-2684. [PubMed: 12771114]

6. Anderson GL, Limacher M, Assaf AR, et al. Effects of conjugated equine estrogen in postmenopausal women with hysterectomy: the Women's Health Initiative randomized controlled trial. JAMA. 2004; 291(14):1701-1712. [PubMed: 15082697]

7. Shumaker SA, Legault C, Rapp SR, et al. Estrogen plus progestin and the incidence of dementia and mild cognitive impairment in postmenopausal women: the Women's Health Initiative Memory Study: a randomized controlled trial. JAMA. 2003; 289(20):2651-2662. [PubMed: 12771112]

8. Daniel JM, Bohacek J. The critical period hypothesis of estrogen effects on cognition: Insights from basic research. Biochim Biophys Acta. 2010; 1800(10):1068-1076. [PubMed: 20100548]

9. Sherwin BB. Estrogen therapy: is time of initiation critical for neuroprotection? Nat Rev Endocrinol. 2009; 5(11):620-627. [PubMed: 19844249]

10. Gibbs RB. Long-term treatment with estrogen and progesterone enhances acquisition of a spatial memory task by ovariectomized aged rats. Neurobiol Aging. 2000; 21(1):107-116. [PubMed: 10794855]

11. Gould E, Woolley CS, Frankfurt M, McEwen BS. Gonadal steroids regulate dendritic spine density in hippocampal pyramidal cells in adulthood. J Neurosci. 1990; 10(4):1286-1291. [PubMed: 2329377] 
12. Woolley CS, McEwen BS. Roles of estradiol and progesterone in regulation of hippocampal dendritic spine density during the estrous cycle in the rat. J Comp Neurol. 1993; 336(2):293-306. [PubMed: 8245220]

13. Adams MM, Shah RA, Janssen WG, Morrison JH. Different modes of hippocampal plasticity in response to estrogen in young and aged female rats. Proc Natl Acad Sci U S A. 2001; 98(14): 8071-8076. [PubMed: 11427724]

14. Leranth C, Shanabrough M, Redmond DE Jr. Gonadal hormones are responsible for maintaining the integrity of spine synapses in the CA1 hippocampal subfield of female nonhuman primates. J Comp Neurol. 2002; 447(1):34-42. [PubMed: 11967893]

15. Choi JM, Romeo RD, Brake WG, Bethea CL, Rosenwaks Z, McEwen BS. Estradiol increases preand post-synaptic proteins in the CA1 region of the hippocampus in female rhesus macaques (Macaca mulatta). Endocrinology. 2003; 144(11):4734-4738. [PubMed: 12960039]

16. Silva I, Mello LE, Freymuller E, Haidar MA, Baracat EC. Onset of estrogen replacement has a critical effect on synaptic density of CA1 hippocampus in ovariectomized adult rats. Menopause. 2003; 10(5):406-411. [PubMed: 14501601]

17. Silva I, Mello LE, Freymuller E, Haidar MA, Baracat EC. Estrogen, progestogen and tamoxifen increase synaptic density of the hippocampus of ovariectomized rats. Neurosci Lett. 2000; 291(3): 183-186. [PubMed: 10984637]

18. Adams MM, Fink SE, Shah RA, et al. Estrogen and aging affect the subcellular distribution of estrogen receptor-alpha in the hippocampus of female rats. J Neurosci. 2002; 22(9):3608-3614. [PubMed: 11978836]

19. Yamaguchi-Shima N, Yuri K. Age-related changes in the expression of ER-beta mRNA in the female rat brain. Brain Res. 2007; 1155:34-41. [PubMed: 17490623]

20. Williams TJ, Mitterling KL, Thompson LI, et al. Age- and hormone-regulation of opioid peptides and synaptic proteins in the rat dorsal hippocampal formation. Brain Res. 2011; 1379:71-85. [PubMed: 20828542]

21. Juraska JM, Lowry NC. Neuroanatomical Changes Associated with Cognitive Aging. Curr Top Behav Neurosci. 2011

22. Raz N, Lindenberger U, Rodrigue KM, et al. Regional brain changes in aging healthy adults: general trends, individual differences and modifiers. Cereb Cortex. 2005; 15(11):1676-1689. [PubMed: 15703252]

23. Resnick SM, Pham DL, Kraut MA, Zonderman AB, Davatzikos C. Longitudinal magnetic resonance imaging studies of older adults: a shrinking brain. J Neurosci. 2003; 23(8):3295-3301. [PubMed: 12716936]

24. Jacobs B, Driscoll L, Schall M. Life-span dendritic and spine changes in areas 10 and 18 of human cortex: a quantitative Golgi study. J Comp Neurol. 1997; 386(4):661-680. [PubMed: 9378859]

25. de Brabander JM, Kramers RJ, Uylings HB. Layer-specific dendritic regression of pyramidal cells with ageing in the human prefrontal cortex. Eur J Neurosci. 1998; 10(4):1261-1269. [PubMed: 9749780]

26. Duan H, Wearne SL, Rocher AB, Macedo A, Morrison JH, Hof PR. Age-related dendritic and spine changes in corticocortically projecting neurons in macaque monkeys. Cereb Cortex. 2003; 13(9):950-961. [PubMed: 12902394]

27. Cupp CJ, Uemura E. Age-related changes in prefrontal cortex of Macaca mulatta: quantitative analysis of dendritic branching patterns. Exp Neurol. 1980; 69(1):143-163. [PubMed: 6771151]

28. Grill JD, Riddle DR. Age-related and laminar-specific dendritic changes in the medial frontal cortex of the rat. Brain Res. 2002; 937(1-2):8-21. [PubMed: 12020857]

29. Markham JA, Juraska JM. Aging and sex influence the anatomy of the rat anterior cingulate cortex. Neurobiol Aging. 2002; 23(4):579-588. [PubMed: 12009507]

30. Wallace M, Frankfurt M, Arellanos A, Inagaki T, Luine V. Impaired recognition memory and decreased prefrontal cortex spine density in aged female rats. Ann N Y Acad Sci. 2007; 1097:5457. [PubMed: 17413010]

31. Wallace M, Luine V, Arellanos A, Frankfurt M. Ovariectomized rats show decreased recognition memory and spine density in the hippocampus and prefrontal cortex. Brain Res. 2006; 1126(1): 176-182. [PubMed: 16934233] 
32. Leranth C, Hajszan T, Szigeti-Buck K, Bober J, MacLusky NJ. Bisphenol A prevents the synaptogenic response to estradiol in hippocampus and prefrontal cortex of ovariectomized nonhuman primates. Proc Natl Acad Sci U S A. 2008; 105(37):14187-14191. [PubMed: 18768812]

33. Tang Y, Janssen WG, Hao J, et al. Estrogen replacement increases spinophilin-immunoreactive spine number in the prefrontal cortex of female rhesus monkeys. Cereb Cortex. 2004; 14(2):215223. [PubMed: 14704219]

34. Hao J, Rapp PR, Leffler AE, et al. Estrogen alters spine number and morphology in prefrontal cortex of aged female rhesus monkeys. J Neurosci. 2006; 26(9):2571-2578. [PubMed: 16510735]

35. Warren SG, Juraska JM. Sex differences and estropausal phase effects on water maze performance in aged rats. Neurobiol Learn Mem. 2000; 74(3):229-240. [PubMed: 11031129]

36. Lowry NC, Pardon LP, Yates MA, Juraska JM. Effects of long-term treatment with 17 betaestradiol and medroxyprogesterone acetate on water maze performance in middle aged female rats. Horm Behav. 2010; 58(2):200-207. [PubMed: 20362580]

37. Bardin CW, Brown T, Isomaa VV, Janne OA. Progestins can mimic, inhibit and potentiate the actions of androgens. Pharmacol Ther. 1983; 23(3):443-459. [PubMed: 6371845]

38. Bamberger CM, Else T, Bamberger AM, Beil FU, Schulte HM. Dissociative glucocorticoid activity of medroxyprogesterone acetate in normal human lymphocytes. J Clin Endocrinol Metab. 1999; 84(11):4055-4061. [PubMed: 10566649]

39. Sitruk-Ware R. Pharmacological profile of progestins. Maturitas. 2004; 47(4):277-283. [PubMed: 15063480]

40. Majewska MD, Harrison NL, Schwartz RD, Barker JL, Paul SM. Steroid hormone metabolites are barbiturate-like modulators of the GABA receptor. Science. 1986; 232(4753):1004-1007. [PubMed: 2422758]

41. Jarrell J. Studies on the developmental pattern of rat ovarian 3 alpha-hydroxysteroid dehydrogenase: inhibition of the postpubertal activity with medroxyprogesterone acetate in vivo. $\mathrm{J}$ Steroid Biochem. 1984; 21(2):151-156. [PubMed: 6237228]

42. Lee TC, Miller WL, Auchus RJ. Medroxyprogesterone acetate and dexamethasone are competitive inhibitors of different human steroidogenic enzymes. J Clin Endocrinol Metab. 1999; 84(6):21042110. [PubMed: 10372718]

43. Penning TM, Sharp RB, Krieger NR. Purification and properties of 3 alpha-hydroxysteroid dehydrogenase from rat brain cytosol. Inhibition by nonsteroidal anti-inflammatory drugs and progestins. J Biol Chem. 1985; 260(28):15266-15272. [PubMed: 2933398]

44. Chisholm NC, Juraska JM. Long term replacement of estrogen in combination with medroxyprogesterone acetate improves acquisition of an alternation task in middle aged female rats. Behav Neurosci. 2011 in press. 10.1037/a0026461

45. Wise PM, Ratner A. Effect of ovariectomy on plasma LH, FSH, estradiol, and progesterone and medial basal hypothalamic LHRH concentrations old and young rats. Neuroendocrinology. 1980; 30(1):15-19. [PubMed: 6986573]

46. Gordon MN, Osterburg HH, May PC, Finch CE. Effective oral administration of 17 beta-estradiol to female C57BL/6J mice through the drinking water. Biol Reprod. 1986; 35(5):1088-1095. [PubMed: 3828426]

47. Liu JW, Dawson DD, Peters CE, Baker MA, Walker AM. Estrogen replacement in ovariectomized rats results in physiologically significant levels of circulating progesterone, and co-administration of progesterone markedly reduces the circulating estrogen. Endocrine. 1997; 6(2):125-131. [PubMed: 9225126]

48. Krettek JE, Price JL. The cortical projections of the mediodorsal nucleus and adjacent thalamic nuclei in the rat. J Comp Neurol. 1977; 171(2):157-191. [PubMed: 64477]

49. Van Eden CG, Uylings HB. Cytoarchitectonic development of the prefrontal cortex in the rat. J Comp Neurol. 1985; 241(3):253-267. [PubMed: 2418068]

50. Markham JA, Morris JR, Juraska JM. Neuron number decreases in the rat ventral, but not dorsal, medial prefrontal cortex between adolescence and adulthood. Neuroscience. 2007; 144(3):961968. [PubMed: 17137726] 
51. Huttenlocher PR. Synaptic density in human frontal cortex - developmental changes and effects of aging. Brain Res. 1979; 163(2):195-205. [PubMed: 427544]

52. Gibson PH. EM study of the numbers of cortical synapses in the brains of ageing people and people with Alzheimer-type dementia. Acta Neuropathol. 1983; 62(1-2):127-133. [PubMed: 6659870]

53. Dumitriu D, Hao J, Hara Y, et al. Selective changes in thin spine density and morphology in monkey prefrontal cortex correlate with aging-related cognitive impairment. J Neurosci. 2010; 30(22):7507-7515. [PubMed: 20519525]

54. Braden BB, Garcia AN, Mennenga SE, et al. Cognitive-impairing effects of medroxyprogesterone acetate in the rat: independent and interactive effects across time. Psychopharmacology (Berl). 2011

55. Braden BB, Talboom JS, Crain ID, et al. Medroxyprogesterone acetate impairs memory and alters the GABAergic system in aged surgically menopausal rats. Neurobiol Learn Mem. 2010

56. Frye CA, Koonce CJ, Walf AA. Mnemonic effects of progesterone to mice require formation of 3alpha,5alpha-THP. Neuroreport. 2010; 21(8):590-595. [PubMed: 20431492]

57. Bamberger CM, Schulte HM. Molecular mechanisms of dissociative glucocorticoid activity. Eur J Clin Invest. 2000; 30 (Suppl 3):6-9. [PubMed: 11281371]

58. Ciriza I, Carrero P, Frye CA, Garcia-Segura LM. Reduced metabolites mediate neuroprotective effects of progesterone in the adult rat hippocampus. The synthetic progestin medroxyprogesterone acetate (Provera) is not neuroprotective. J Neurobiol. 2006; 66(9):916-928. [PubMed: 16758493]

59. Nilsen J, Brinton RD. Divergent impact of progesterone and medroxyprogesterone acetate (Provera) on nuclear mitogen-activated protein kinase signaling. Proc Natl Acad Sci U S A. 2003; 100(18):10506-10511. [PubMed: 12925744]

60. Nilsen J, Brinton RD. Impact of progestins on estradiol potentiation of the glutamate calcium response. Neuroreport. 2002; 13(6):825-830. [PubMed: 11997695]

61. Liu L, Zhao L, She H, et al. Clinically relevant progestins regulate neurogenic and neuroprotective responses in vitro and in vivo. Endocrinology. 2010; 151(12):5782-5794. [PubMed: 20943809]

62. Jodhka PK, Kaur P, Underwood W, Lydon JP, Singh M. The differences in neuroprotective efficacy of progesterone and medroxyprogesterone acetate correlate with their effects on brainderived neurotrophic factor expression. Endocrinology. 2009; 150(7):3162-3168. [PubMed: 19325006]

63. Pazol K, Northcutt KV, Patisaul HB, Wallen K, Wilson ME. Progesterone and medroxyprogesterone acetate differentially regulate alpha4 subunit expression of GABA(A) receptors in the CA1 hippocampus of female rats. Physiol Behav. 2009; 97(1):58-61. [PubMed: 19394921]

64. Gibbs RB. Effects of estrogen on basal forebrain cholinergic neurons vary as a function of dose and duration of treatment. Brain Res. 1997; 757(1):10-16. [PubMed: 9200493]

65. Morissette M, Di Paolo T. Effect of chronic estradiol and progesterone treatments of ovariectomized rats on brain dopamine uptake sites. J Neurochem. 1993; 60(5):1876-1883. [PubMed: 8473903]

66. Woolley CS, McEwen BS. Estradiol mediates fluctuation in hippocampal synapse density during the estrous cycle in the adult rat. J Neurosci. 1992; 12(7):2549-2554. [PubMed: 1613547]

67. Stone DJ, Rozovsky I, Morgan TE, Anderson CP, Finch CE. Increased synaptic sprouting in response to estrogen via an apolipoprotein E-dependent mechanism: implications for Alzheimer's disease. J Neurosci. 1998; 18(9):3180-3185. [PubMed: 9547226]

68. Rapp PR, Morrison JH, Roberts JA. Cyclic estrogen replacement improves cognitive function in aged ovariectomized rhesus monkeys. J Neurosci. 2003; 23(13):5708-5714. [PubMed: 12843274]

69. Luine V, Attalla S, Mohan G, Costa A, Frankfurt M. Dietary phytoestrogens enhance spatial memory and spine density in the hippocampus and prefrontal cortex of ovariectomized rats. Brain Res. 2006; 1126(1):183-187. [PubMed: 16945354]

70. Srivastava DP, Woolfrey KM, Liu F, Brandon NJ, Penzes P. Estrogen receptor ss activity modulates synaptic signaling and structure. J Neurosci. 2010; 30(40):13454-13460. [PubMed: 20926671] 
71. Liu F, Day M, Muniz LC, et al. Activation of estrogen receptor-beta regulates hippocampal synaptic plasticity and improves memory. Nat Neurosci. 2008; 11(3):334-343. [PubMed: 18297067]

72. Cheng CM, Mervis RF, Niu SL, et al. Insulin-like growth factor 1 is essential for normal dendritic growth. J Neurosci Res. 2003; 73(1):1-9. [PubMed: 12815703]

73. O'Kusky JR, Ye P, D’Ercole AJ. Insulin-like growth factor-I promotes neurogenesis and synaptogenesis in the hippocampal dentate gyrus during postnatal development. J Neurosci. 2000; 20(22):8435-8442. [PubMed: 11069951]

74. Sonntag WE, Lynch CD, Bennett SA, et al. Alterations in insulin-like growth factor-1 gene and protein expression and type 1 insulin-like growth factor receptors in the brains of ageing rats. Neuroscience. 1999; 88(1):269-279. [PubMed: 10051206]

75. Selvamani A, Sohrabji F. The neurotoxic effects of estrogen on ischemic stroke in older female rats is associated with age-dependent loss of insulin-like growth factor-1. J Neurosci. 2010; 30(20):6852-6861. [PubMed: 20484627]

76. Malarkey WB, Burleson M, Cacioppo JT, Poehlmann K, Glaser R, Kiecolt-Glaser JK. Differential effects of estrogen and medroxyprogesterone on basal and stress-induced growth hormone release, IGF-1 levels, and cellular immunity in postmenopausal women. Endocrine. 1997; 7(2):227-233. [PubMed: 9549049]

77. Mozzanega B, Babbo GL, Salmaso L, et al. Oral 17beta-estradiol and sequential progesterone in menopause: effects on insulin-like growth factors and their binding proteins. Gynecol Endocrinol. 2007; 23(1):50-57. [PubMed: 17484513]

78. Keenan PA, Ezzat WH, Ginsburg K, Moore GJ. Prefrontal cortex as the site of estrogen's effect on cognition. Psychoneuroendocrinology. 2001; 26(6):577-590. [PubMed: 11403979] 

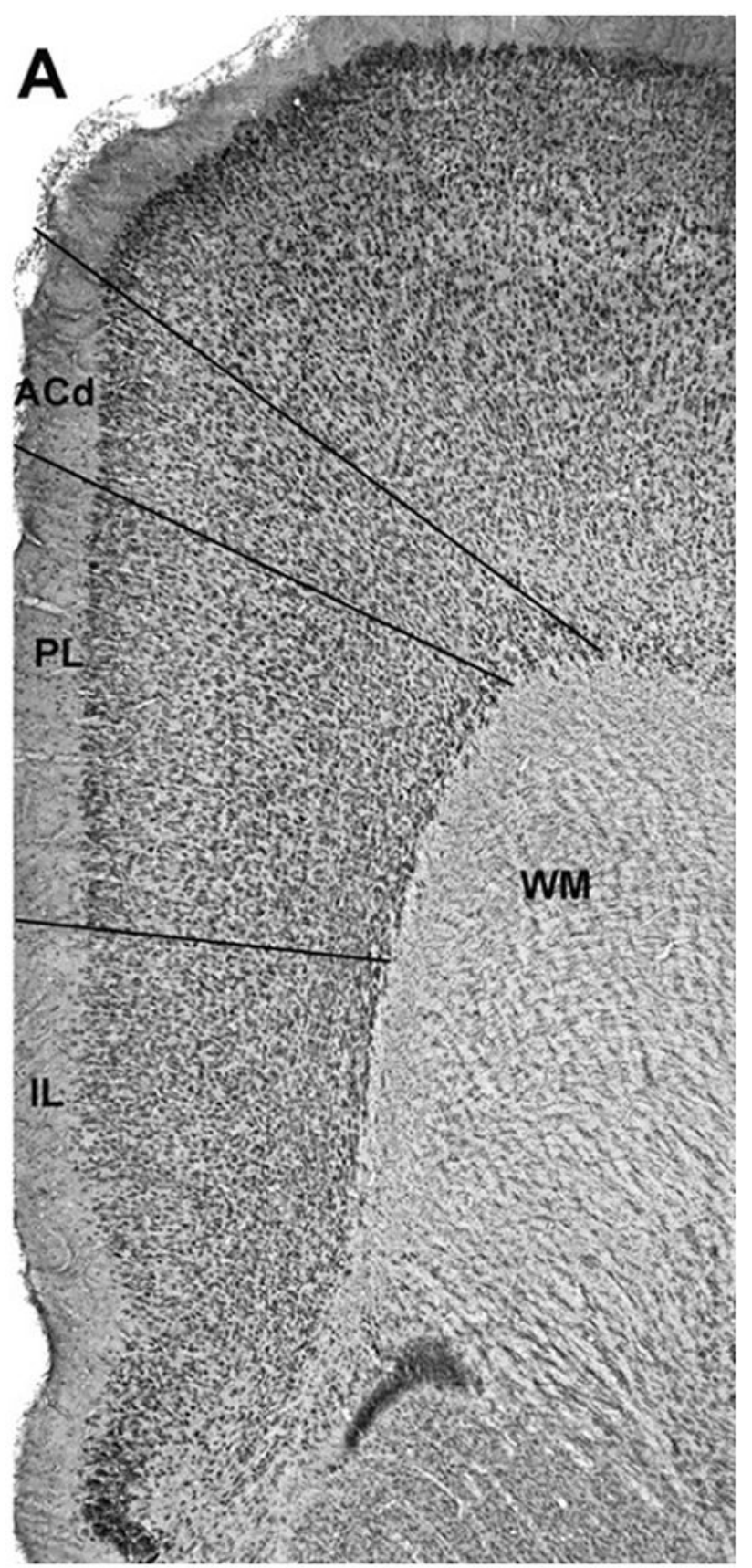

Figure 1.

Coronal section, cut at 60 microns, through the medial prefrontal cortex with cell bodies stained using Methylene blue/Azure II. Borders of the prelimbic and infralimbic regions are shown based on the cytoarchitectonic characteristics revealed by this stain ${ }^{48,49}$. Reprinted from Markham et al. ${ }^{50}$. 


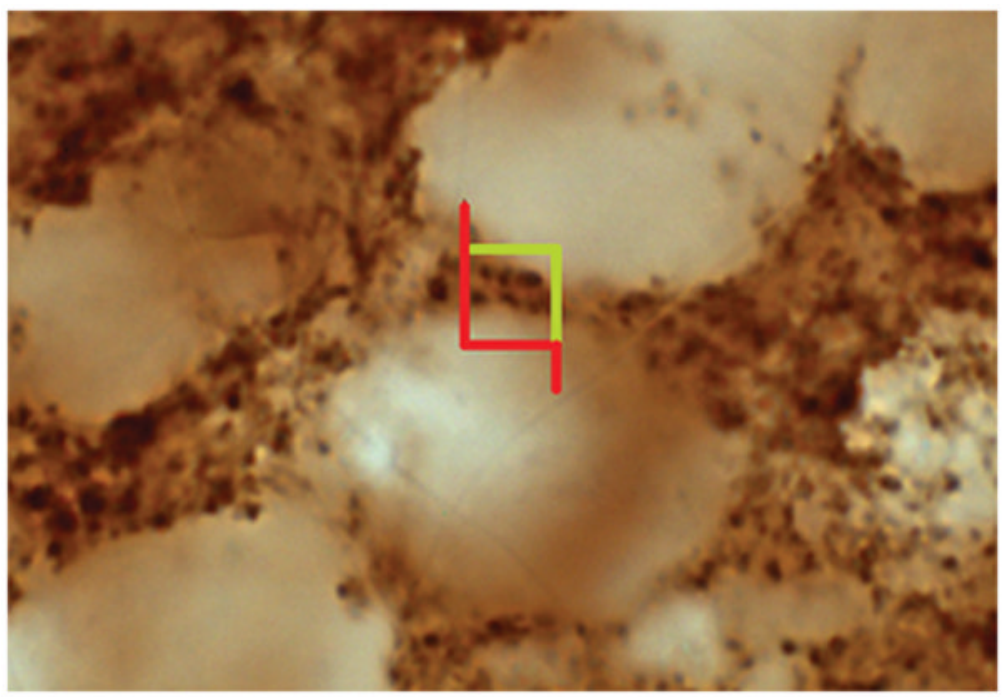

Figure 2.

High magnification image of the mPFC stained for synaptophysin, a membrane component of synaptic vesicles. The counting frame used to stereologically quantify the number of boutons was $4 \mu \mathrm{m}$ by $4 \mu \mathrm{m}$. 


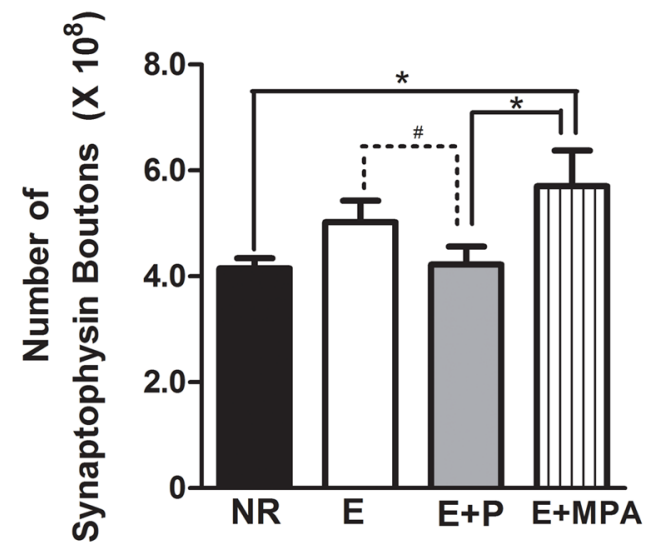
No Replacement
$\square$ Estradiol $\left(\mathrm{E}_{2}\right)$
$\square E_{2}$ and Progesterone
而 $\mathrm{E}_{2}$ and MPA

Figure 3.

Total number (mean + SEM) of synaptophysin labeled synaptic boutons in the mPFC. Animals receiving $\mathrm{E}_{2}+$ MPA had more synaptophysin boutons than those receiving no replacement and $\mathrm{E}_{2}+\mathrm{P}$. There was a non significant trend for animals receiving estrogen alone to have more synaptophysin boutons than those receiving $\mathrm{E}_{2}+\mathrm{P}\left({ }^{*} \mathrm{p}<.03\right.$, \#p <.09). 
A

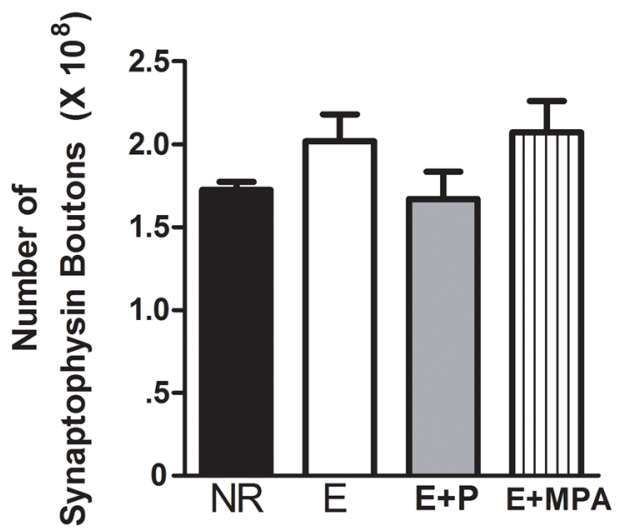

B

No Replacment

$\square$ Estradiol $\left(\mathrm{E}_{2}\right)$

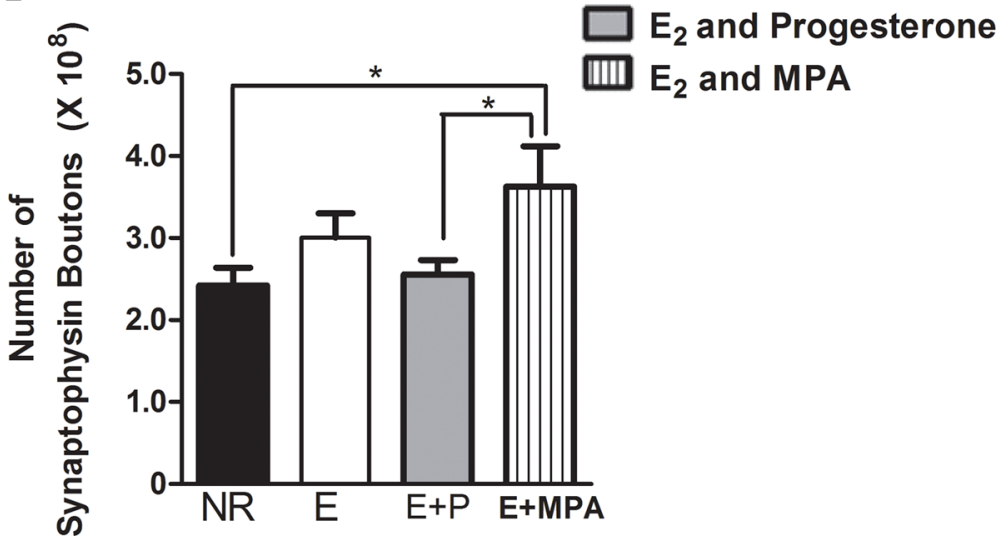

Figure 4.

Figure 4 A. Total number (mean + SEM) of synaptophysin labeled synaptic boutons in Layers $2 / 3$ of the mPFC. Hormone treatment did not significantly alter the number of synapses. B. Total number (mean + SEM) of synaptophysin labeled boutons in Layers $5 / 6$ of the mPFC. Animals receiving $E_{2}+$ MPA had more synaptophysin labeled boutons that those receiving no replacement and $\mathrm{E}_{2}+\mathrm{P}(* \mathrm{p}<.02)$. 


\section{Table 1}

Body and Uterine Weight

\begin{tabular}{ccc}
\hline Hormone Group & Mean Body Weight $(\mathrm{g})$ & Mean Uterine Weight $(\mathbf{g})$ \\
\hline No replacement & $619.6 \pm 37.7$ & $.05 \pm .01$ \\
\hline Estrogen & $501.8 \pm 35.0^{*}$ & $.12 \pm .02^{*}$ \\
\hline Estrogen \& P & $472.7 \pm 28.1^{*}$ & $.11 \pm .01^{*}$ \\
\hline Estrogen \& MPA & $451.3 \pm 66.2^{*}$ & $.12 \pm .02^{*}$ \\
\hline
\end{tabular}

Body and uterine weights were taken at sacrifice for all groups. The no replacement animals weighed significantly more and had lower uterine weights than all hormone treated groups.

p $<.01$ 